\title{
Transient obturator nerve block with fascia iliaca compartment block following local infiltration for open inguinal herniorrhaphy
}

\author{
Takeshi Murouchi(D)
}

\begin{abstract}
Background: Ilioinguinal nerve block is effective for analgesia after open inguinal herniorrhaphy. However, transient femoral nerve palsy can happen after the block. The ambulatory patients sometimes cannot discharge from the hospital with the motor deficiency. Here is described a case of fascia iliaca compartment block with complete obturator nerve block after surgical infiltration analgesia for open inguinal herniorrhaphy.
\end{abstract}

Case presentation: An ambulatory open inguinal herniorrhaphy was performed for a 63-year-old male under general anesthesia. The mixture of short-/long-acting local anesthetics was injected by the surgeon into the subcutaneous tissue, between the Camper's and Scarpa's fasciae, into the inguinal canal, and between the internal oblique and transversus abdominis muscles. The patient could not adduct his ipsilateral hip joint at all $1 \mathrm{~h}$ after emergence. The flexion of the hip joint was weakened two more hours later, and numbness of the lateral thigh emerged. The complications completely resolved $7 \mathrm{~h}$ after surgery.

Conclusions: Surgical infiltration analgesia as well as percutaneous ilioinguinal nerve block can cause both fascia iliaca plane block and obturator nerve block. Analgesia regimen should be carefully built for ambulatory surgery.

Keywords: Transient femoral nerve palsy, llioinguinal nerve block, Inguinal herniorrhaphy

\section{Background}

Transient femoral nerve palsy is a known complication after ilioinguinal/iliohypogastric nerve block. Here is described a weak fascia iliaca compartment block (FICB) with complete obturator nerve block (ONB) after local infiltration for open inguinal herniorrhaphy.

\section{Case presentation}

Written informed consent was obtained from the patient for the publication of this case report.

An otherwise healthy 63-year-old man $(166.7 \mathrm{~cm} /$ $54 \mathrm{~kg}$ ) with left inguinal hernia was planned to undergo an ambulatory open herniorrhaphy. General anesthesia combined with local infiltration was planned, according to the rule of the hospital for ambulatory herniorrhaphy.

Premedication was not given. Standard monitors were attached to the patient on entering the operating room.

Correspondence: g-fields@fc4.so-net.ne.jp

Department of Anesthesiology, Asahi General Hospital, I-1326, Asahi, Chiba 289-2511, Japan
Anesthesia was induced with $140 \mathrm{mg}$ of propofol, and $50 \mathrm{mcg}$ of fentanyl after the venous access was established. The airway was secured with supraglottic airway after muscle relaxation had been acquired with $0.9 \mathrm{mg} /$ $\mathrm{kg}$ of rocuronium. Anesthesia was maintained with 5\% desflurane, and mechanical ventilation by pressure control was maintained throughout the surgery. The local anesthetic mixture was made from $10 \mathrm{~mL}$ of $0.75 \%$ ropivacaine and $10 \mathrm{~mL}$ of $1 \%$ lidocaine with adrenaline 1:200,000. The surgeon administered $5 \mathrm{~mL}$ of the mixture into the subcutaneous tissue before the incision, $3 \mathrm{~mL}$ between Camper's fascia and Scarpa's fascia, and $2 \mathrm{~mL}$ into the inguinal canal. The rest of the mixture $(10 \mathrm{~mL})$ was administered with intense pressure between the internal oblique and transversus abdominis muscles at the end of the surgery before skin closure. Another $50 \mathrm{mcg}$ of fentanyl was administered intraoperatively, and $0.5 \mathrm{mg}$ of droperidol was administered before emergence. Surgery was performed with only slight changes in heart rate and blood pressure. The muscle relaxation was reversed with $200 \mathrm{mg}$ of Sugammadex at the end of 
the surgery. The patient was extubated after stable spontaneous respiration, and good emergence was confirmed. The patient seemed to be able to perform the adduction and abduction of his shoulders, and the extension and flexion of his elbows, hips, knees, and ankles at this point. The duration of the surgery was 45 mins, and anesthetic time was 70 mins. The patient was transferred to the postanesthetic care unit without trouble.

The patient condition was observed $1 \mathrm{~h}$ after the transfer. The mental status was alert with E4V5M6 at Glasgow coma scale. He experienced no postoperative nausea and vomiting. There was a slight dull pain around the surgical wound, which soon resolved after $1000 \mathrm{mg}$ of rescue acetaminophen. He was able to drink clear water without nausea or aspiration. Although the patient was able to walk to the restroom with the drip stand and void without trouble, he complained of discomfort in his left thigh. The physical examination revealed that we had not recognized that he could adduct his left hip joint poorly with grade 1 at the manual muscle test (MMT) without any apparent sensory deficit in the left leg. His leg flexion, knee extension, and the sensation of the lateral and medial thigh were normally maintained. Three hours after the surgery, the adduction of the hip recovered to MMT 3. However, the patient could not perform ipsilateral leg flexion nor knee extension against moderate pressure (MMT 4), and there was slight hypoesthesia in the lateral thigh. Seven hours after the surgery, both the muscle weakness and hypoesthesia completely resolved. The patient had not experienced any pain after the first rescue. The patient strongly wished to discharge from the hospital and discharged without trouble.

\section{Discussion}

Transient femoral nerve palsy (TFP) is a rare complication after ilioinguinal nerve block [1]. The complication had been reported after both of percutaneous block [1-3] and surgical field block [4]. The incidence of TFP is reported to be around $3-5 \%$ in pediatric population [2]. However, there had been no previous report of fascia iliaca compartment block with obturator nerve block as observed in this case.

The mechanism of this complication is considered as multifactorial. The cause of complete ONB, in this case, was considered due to the intraabdominal dissemination of the local anesthetic mixture after the peritoneal dissection around the pubis. The obturator nerve, along with the obturator artery and vein, runs toward the superior pubic ramus and pierces the obturator internus muscle. The injected local anesthetic was estimated to infiltrate into the abdominal cavity and affect the obturator nerve, adjacent to the incision at this point. The mechanism of FICB is considered to the spread of the local anesthetic toward the lateral edge of the psoas major muscle between the transversus abdominis muscle and the continuum of the transversalis fascia/fascia iliaca [5]. Ultrasound has also revealed that a large volume of the local anesthetic can spread into the femoral triangle [4]. The slow and incomplete effect of the FICB in this case could be the result of the relatively small amount of the injected local anesthetic. Three hours after the administration of the local anesthetic is extraordinarily late for the onset of a block. The frequent active movement of the hip joint by the patient after he noticed the muscle weakness of the adductors could have facilitated the spread of the small amount of local anesthetic toward the psoas major muscle.

The utilization of ultrasound guidance for percutaneous ilioinguinal nerve block was reported to decrease the incidence of TFP [6]. It is also estimated that smaller amount of the local anesthetic should be administered for the prevention of inadvertent spread toward the femoral triangle or the psoas major muscle. The injection of local anesthetic after the surgical incision of the related fasciae should be avoided to prevent the inadvertent intraperitoneal spread as in this case. After this case, our hospital has changed the analgesic regimen from the intramuscular injection to subcutaneous dissemination before the wound closure. To our knowledge, an ONB with FICB after local infiltration for open herniorrhaphy has not been reported. Although both regional anesthesia and local infiltration technique are mandatory for reduced opioid usage, it is also essential to build an effective, but motor-sparing analgesic regimen for ambulatory surgery.

\section{Abbreviations}

FICB: Fascia iliaca compartment block; MMT: Manual muscle test;

ONB: Obturator nerve block; TFP: Transient femoral nerve palsy

\section{Availability of data and materials}

The data related to the article is recorded in the electric medical record in Asahi General Hospital. However, the browsing of the data is restricted to the related medical staffs.

Author's contribution

The author read and approved the final manuscript.

Ethics approval and consent to participate Not applicable.

Consent for publication

Written informed confirmation for this publication was gained from the patient.

Competing interests

The author declares that he have no competing interests.

\section{Publisher's Note}

Springer Nature remains neutral with regard to jurisdictional claims in published maps and institutional affiliations. 
Received: 2 August 2018 Accepted: 27 August 2018

Published online: 31 August 2018

\section{References}

1. Rosario DJ, Skinner PP, Raftery AT. Transient femoral nerve palsy complicating preoperative ilioinguinal nerve blockade for inguinal herniorrhaphy. Br J Surg. 1994;81(6):897. http://www.ncbi.nIm.nih.gov/ pubmed/8044615

2. Leng SA. Transient femoral nerve palsy after ilioinguinal nerve block. Anaesth Intensive Care. 1997;25(1):92. http://www.ncbi.nlm.nih.gov/ pubmed/9075530

3. Shivashanmugam T, Kundra P, Sudhakar S. lliac compartment block following ilioinguinal iliohypogastric nerve block. Pediatr Anesth. 2006; 16(10):1084-6. https://doi.org/10.1111/j.1460-9592.2006.01925.x.

4. Olsen D, Amundson A, Kopp S. Inadvertent prolonged femoral nerve palsy after field block with liposomal bupivacaine for inguinal herniorrhaphy. A A Case Rep. 2016;6(11):362-3. https://doi.org/10.1213/XAA.0000000000000316.

5. Rosario DJ, Jacob S, Luntley J, Skinner PP, Raftery AT. Mechanism of femoral nerve palsy complicating percutaneous ilioinguinal field block. $\mathrm{Br} J$ Anaesth. 1997;78(3):314-6. https://doi.org/10.1093/bja/78.3.314

6. Tani M, Sato M, Son I, et al. Transient femoral nerve palsy after ilioinguinal-iliohypogastric nerve block: comparison of ultrasound-guided and landmark-based techniques in adult inguinal hernia surgery. Masui. 2015;64(6):603-9. http://www.ncbi.n/m.nih.gov/pubmed/26437548

\section{Submit your manuscript to a SpringerOpen ${ }^{\circ}$ journal and benefit from:}

- Convenient online submission

- Rigorous peer review

- Open access: articles freely available online

- High visibility within the field

- Retaining the copyright to your article

Submit your next manuscript at $\boldsymbol{\nabla}$ springeropen.com 